\title{
MEDICAL TOURISM: ITS RESEARCH AND IMPLICATIONS FOR PUBLIC HEALTH
}

\author{
Blanka Klímová1, Kamil Kuča ${ }^{2,3}$ \\ 1Department of Applied Linguistics, Faculty of Informatics and Management, University of Hradec Králové, Hradec Králové, Czech Republic \\ 2Biomedical Research Centre, University Hospital Hradec Králové, Hradec Králové, Czech Republic \\ ${ }^{3}$ Centre for Basic and Applied Research, Faculty of Informatics and Management, University of Hradec Králové, Hradec Králové, Czech Republic
}

\section{SUMMARY}

Objective: The purpose of this article is to describe current research trends in medical tourism and implications for public health, especially in destination countries.

Methods: The methods used for this article include a literature review of available sources on the research topic in the world's acknowledged databases Web of Science, Scopus, MEDLINE, and ScienceDirect.

Results: The findings indicate that there is no consensus on the definition of medical tourism. However, there are a few conceptual models which can be used in further medical tourism research and practice. The findings also reveal that there are still certain issues, which hinder the fast growth of medical tourism, such as unclear impact on healthcare systems, ethical concerns or a lack of effective tools for the measurement of quality assurance of the medical tourism services and their products.

Conclusions: There is a need for data collection on medical tourism, both at national and worldwide level to provide a realistic picture of this evolving field of tourism as well as implications for public health in destination countries.

Key words: medical tourism, research, trends, barriers, implications

Address for correspondence: K. Kuča, University Hospital, Sokolská 581, Hradec Králové, Czech Republic. E-mail: kamil.kuca@fnhk.cz

https://doi.org/10.21101/cejph.a5744

\section{INTRODUCTION}

There have been several attempts to define medical tourism (1). From the narrower point of view, medical tourism is used to describe people travelling to other country than their own in order to receive relevant medical treatment (2-4). From the broader perspective, medical tourism is seen as a vacation with travelling across international borders to obtain a wide range of medical services such as leisure, fun, relaxation activities, wellness, and healthcare services (5). Therefore, there is no consensus on the definition of medical tourism. The reason is that medical tourism travel is influenced by other factors. For example, the Mexican diaspora living close to the USA and Mexican borders often travels to receive medical treatment especially due to financial reasons in their home country (6). On the contrary, the Turkish diaspora travels home mainly due cultural differences, which includes language or food preferences (7). The discrepancy in the definition of medical tourism can be also caused by disagreement on the types of medical procedures since non-invasive, usually one day procedures, such as dentistry or small cosmetic surgeries can enable a medical tourist enjoy sightseeing in the destination after the medical intervention. On the contrary, the medical tourist who has to undergo a more serious medical intervention might not prefer leisure or other fun activities and would rather go home.

Nevertheless, medical tourism is part of a broader term, known as health tourism, which was defined by Carrera and Bridges (8) as "the organized travel outside one's local environment or restoration of an individual's well-being in mind and body". Thus, apart from the medical treatment, health tourism includes prevention, relaxation or convalescence, as well as wellness and spa industry. Szymanska (9) also expands this distribution with aesthetic medicine for its growing importance on the health tourism market. Generally, health and wellness tourism are considered soft in comparison with medical interventions of medical tourism (10). Figure 1 illustrates the key components of health tourism and their hierarchy.

The disagreement on one common definition of medical tourism is also based on imprecise and unreliable numbers of medical tourists since no country provides official data on medical tour-

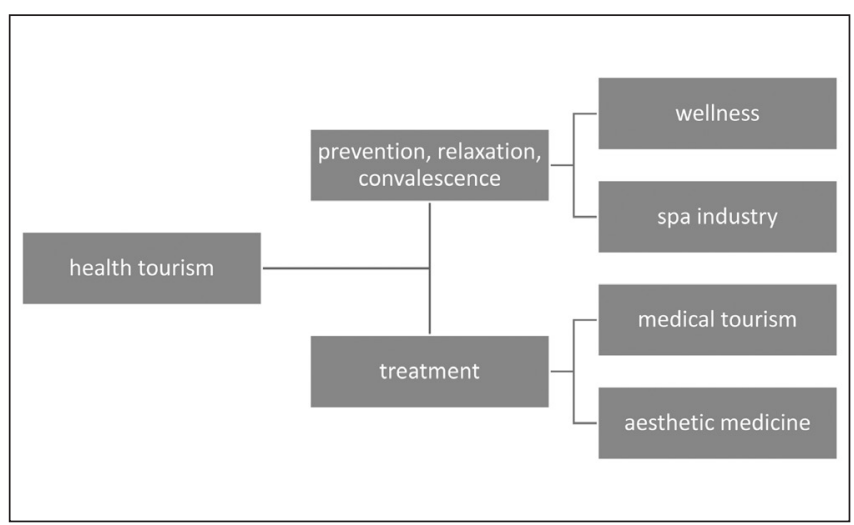

Fig. 1. Key components of health tourism.

Authors' own processing. 
ism. The reason is that hospitals do not produce data verified by an independent body and there are no means to collect them (1).

Currently, medical tourism is a rapidly expanding branch of tourism. In fact, it appears to be a significant source of national revenue because the medical tourist's expenditure is usually three times higher than the one of the common tourist (11). As Gaines and Nguyen (12) claim, this multibillion-dollar phenomenon is expected to grow significantly in the next 5-10 years. For example, in 2015 medical tourism generated the revenue of 60-70 billion US dollars and this revenue should be twofold higher in 2020 . Annually, there are about 50 million medical tourists worldwide seeking treatment in other country than their own (13). This is caused by several motivation reasons: low cost treatment in other, usually less developed countries, fewer barriers to travel, shorter waiting periods, inability to undergo the treatment intervention in the home country, availability of the state-of-the-art medical equipment and facilities accredited by the Joint Commission International, better quality care of medical interventions than in one's own country, western trained doctors who can speak several languages, or availability of post-intervention care and rest $(14,15)$.

Furthermore, the exact impact of medical tourism on healthcare systems in destination countries has not yet been described since there is a lack of data and empirical analyses on this issue. Nevertheless, certain benefits of medical tourism for public health do exist. These include local career opportunities for health workers, additional resources for healthcare infrastructure, as well as enhancement of quality of care both in public and private sectors (16). The purpose of this article is to describe current research trends in medical tourism and implications for public health, especially in destination countries.

\section{MATERIALS AND METHODS}

The methodology of this review study is based on the work of Moher et al. (17). The methods used for this article include a literature review of available sources on the research topic in the world's acknowledged databases Web of Science, Scopus, MEDLINE, and ScienceDirect. The search was based on the key words: health tourism and medical tourism in the period of 2000 till the end of December 2016. The search starts with the year of 2000 although Lunt et al. (18) argue that the research evidence in the field of medical tourism dates back to 2010. Nevertheless, there is evidence of older studies in this field $(3,8,19)$. Therefore, older studies dating back to 2000 were also searched for in this review. Figure 2 demonstrates an interest in medical tourism research in the form of an increase in the number of research studies on medical tourism found in ScienceDirect from 2000 till 2016, which is particularly striking for the period of 2000-2015.

Majority of the studies were detected in the database ScienceDirect, specifically 26,836 studies, in Scopus 5,819 studies were identified, followed by MEDLINE with 3,264 studies and finally, the Web of Science with 2,716 studies. Figure 3 then illustrates the selection procedure of the final number of studies, which was done in the following steps:

- identification (identification of the relevant studies on the basis of the key words and consequently, on the basis of the titles);

- duplication check (the same articles were included only once);

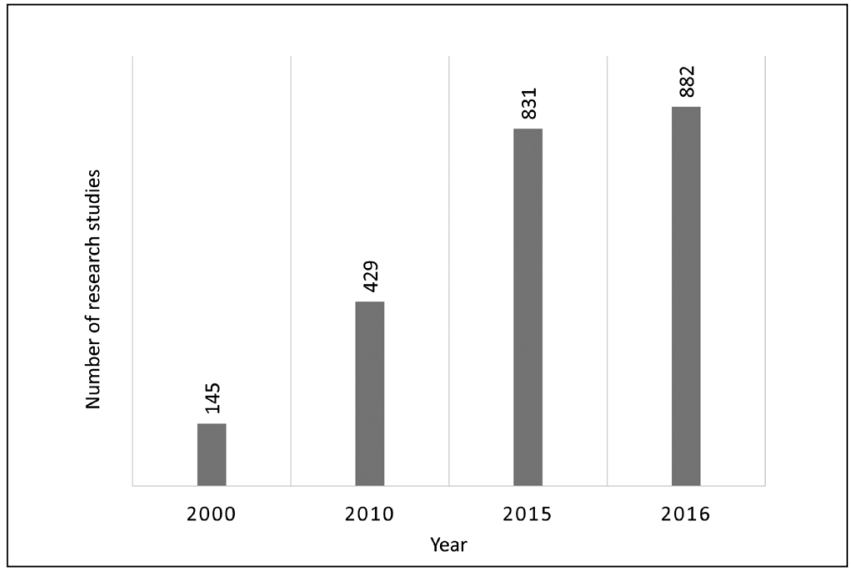

Fig. 2. Number of research studies on medical tourism between 2000 and 2016.

Authors' own processing based on the data from ScienceDirect (20).

- assessment of relevancy (verification on the basis of abstracts whether the selected study corresponds to the set goal (Fig. 3).

Eventually, 32 studies remained for the full-length analysis. In addition, the author used the information from four web pages which referred to the research topic $(12,13)$.

In addition, the authors conducted research in the Web of Science as far as the number of articles per each world's country is concerned. Most of the research studies originated in the English speaking countries such as the USA (247), Canada (94), England (85), and Australia (71). These countries were then followed by five Asian countries: Malaysia (44), South Korea (35), Taiwan (31), China (30), and India (30). Then other research studies were identified in Europe: the Netherlands (27), Germany (27), France (24), Italy (19), Swizerland (18), Romania (16), or Poland (15).

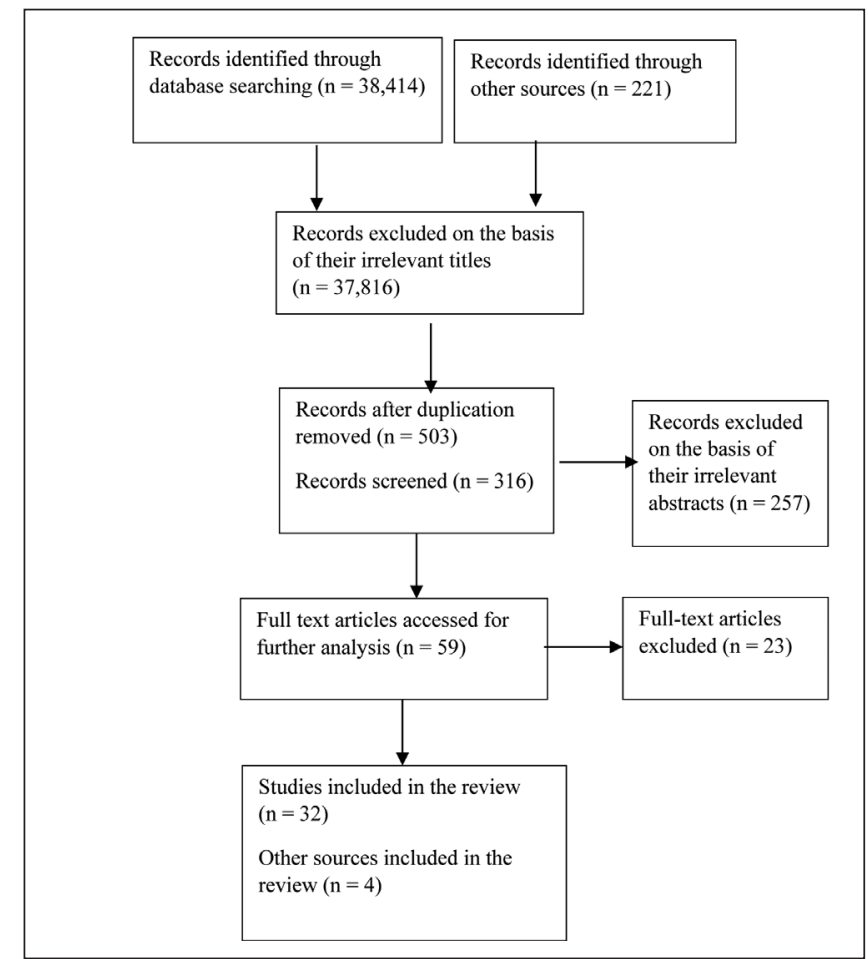

Fig. 3. Results of the selection procedure.

Authors' own processing. 
The findings suggest that especially these countries should be involved in medical tourism, which is confirmed by other results described in the following section.

\section{RESULTS AND DISCUSSION}

In the past, research in the field of medical tourism predominantly focused on its conceptualization, motivation factors, commodification, potential markets and their cost analysis $(1,4,19$, 21). Several theoretical attempts have been especially made in designing conceptual models for performing research in the field of medical tourism. So far five such models have been proposed. Smith and Forgione (22) in their decision-making model indicate that medical tourists select the destination first on the basis of its economic conditions, political climate and regulatory policies, and only afterwards they take into account medical facilities or infrastructure. The second model designed by Caballero-Danell and Mugomba (23) is based on the market structure of the medical tourism industry and includes all of the stakeholders. The third model by Ye et al. (24) considers the push-and-pull motivational factors of medical tourists in their destination choice, such as hardware of the hospital, word-of-mouth information, attractive price of cosmetic procedures, or privacy. The fourth model designed by Heung et al. (5) considers both supply and demand sides that can provide a complete picture of medical tourism in an individual country or region. The fifth model developed by Pocock and Phua (16) offers a conceptual framework that outlines the policy implications of medical tourism's growth for health systems based on the cases of Thailand, Singapore and Malaysia. In comparison with the previous models, which concentrated on the impact of targeted, vertical interventions in health systems, this last model is significant since it provides a basis for empirical studies weighing the benefits and disadvantages of medical tourism for health systems. Nevertheless, none of these models have been further researched and implemented in practice yet.

Thanks to a relatively good global market with medical tourism procedures, current medical tourism research thus concentrates on the competitiveness and diversification in the offer of these medical tourism procedures and interventions (25). As Connell (1) states, "no health care sector is as competitive and consumeroriented as medical tourism, since some procedures do not need be undertaken, and most are possible in many countries, usually including home countries". The most competitive countries in this respect seem to be India (cost savings can reach $90 \%$ in comparison with the US medical costs; eye surgery and surrogacy), Singapore (excellent robotic surgery), China (stem cell transplantation), Thailand (sex change intervention), Israel (use of the effects of the Dead Sea), Brazil (cosmetic surgery), the Czech Republic (donated female egg), Hungary (dental work), Croatia (use of greater local anesthesia), Germany (excellence in medical interventions), or Turkey (post-care convalescence by the sea, religious reasons) (11). And other medical tourism destinations are on their rise such as Malaysia, the Kingdom of Saudi Arabia (26), South Africa, Greece, Romania, or Bulgaria (27). However, as Connell (1) claims, most of medical tourism is still short distance and diasporic where the cultural context enables ease of communication and understanding medical procedures and enable these medical tourists to see their families and friends.
In addition, the present research in the field of medical tourism focuses on the exploration of barriers which hinder its development. These barriers include a low level of private hospital websites promoting medical tourism (28) or a lack of online word-of-mouth recommendations which could have a positive effect on destination trust and intention to travel to these countries (29). Although most of young and middle-aged people are now digitally competent, most of the tourists, including medical tourists in particular, still prefer word-of-mouth as a primary source of information (30). This has been confirmed by other researchers in this field $(1,31,32)$. Other factors include a lack of trust and quality of medical interventions (14), a lack of cooperation between the public and private subjects in the destination (33), or as it has been already mentioned, cultural distance (7). The research (34) indicates that the healthcare providers should possess both clinical and non-clinical abilities. Particularly, the latter reflect that the healthcare providers do not have enough awareness of cultural differences of their clients with different cultural and social backgrounds.

The findings of research studies also reveal that medical tourism has both positive and negative impact on healthcare systems in destination countries, as well as certain risks, including medical tourists themselves. The positive outcomes include offering solutions to problems; in destination countries, medical tourism can namely contribute to the development of healthcare infrastructure, it can set a standard of care through seeking accreditation; destination countries can develop a standard of care, including facility of aesthetics. On the contrary, medical tourism is a user of public sources, and brain drain trained medical staff from public to private sector (35).

Furthermore, Crooks et al. (36) list certain risks which healthcare systems and medical tourists might face. These are as follows:

- considerable public consequences if healthcare facilities in departing countries must use resources treating postoperative complications;

- medical tourists may come back home with certain diseases, such as infections, which may pose a risk of exposure to infections that are refractory to standard treatment procedures and thus cause significant public health risks;

- limited health literacy of medical tourists and access to accurate information may lead to their inability to make an informed decision about medical tourism and ultimately to accept the risks of going abroad and providing informed consent.

Especially the last point described above represents a serious ethical and legal issue. If problems arise, medical tourists may lack the chance to seek damages in malpractice lawsuits, due to the multiple jurisdictions involved and the lack of clarity in terms of which law should apply. Another ethical issue concerns accreditation and quality of care, including the role and responsibilities of medical tourism facilitators in the whole process (37). These medical tourism facilitators act as moderators between a medical tourist and health providers in the destination. They help medical tourists find reliable providers and ensure their trouble-free arrangements (38), but in most cases they lack relevant training, they do not provide completely transparent information on their websites, or distance from liability risks (37). Furthermore, as the research (39) indicates, conflictual relations might arise between these facilitators and medical professionals who are not willing to cooperate with these facilitators. 


\section{CONCLUSION}

The findings show that due to different views on the perception of medical tourism, there is no consensus on the definition of medical tourism. The results of this study also indicate that there are still certain issues which hinder the fast growth of medical tourism, such as its unclear impact on healthcare systems, ethical concerns or a lack of effective tools for the measurement of quality assurance of the medical tourism services and their products. Moreover, there is a need for data collection on medical tourism, both at national and worldwide level in order to provide a realistic picture of this evolving field of tourism as well as implications for public health in destination countries. Thus, the future research should concentrate on performing empirical studies, which would analyze, evaluate and provide implications of the effect of medical tourism on destinations' healthcare systems and public health outcomes, taking in consideration all ethical and legal issues.

\section{Acknowledgement}

This paper was supported by the SPEV project 2020 run at the Faculty of Informatics and Management, University of Hradec Králové, Czech Republic, and by the long-term development plan FNHK. The authors thank Josef Toman for his help with data processing.

\section{Conflict of Interests}

None declared

\section{REFERENCES}

1. Connell J. Contemporary medical tourism: conceptualisation, culture and commodification. Tour Manag. 2013;34:1-13.

2. Al-Lamki L. Medical tourism. Beneficence or maleficence? Sultan Qaboos Univ Med J. 2011;11(4):444-7.

3. Connell J. Medical tourism: sea, sun, sand and ... surgery. Tour Manag. 2006;27(6):1093-100.

4. Lunt N, Smith R, Exworthy M, Green ST, Horsfall D, Mannion R. Medical tourism: treatments, markets and health system implications: a scoping review. OECD; 2011.

5. Heung VCS, Kucukusta D, Song H. A conceptual model of medical tourism: implications for future research. J Travel Tour Mark. 2010;27(3):23651.

6. Horton S, Cole S. Medical returns: seeking health care in Mexico. Soc Sci Med. 2011;72(11):1846-52.

7. Esiyok B, Cakar M, Kurtulmusoglu FB. The effect of cultural distance on medical tourism. J Destin Mark Manag. 2017;6(1):66-75.

8. Carrera PM, Bridges JF. Globalization and healthcare: understanding health and medical tourism. Expert Rev Pharmacoecon Outcomes Res. 2006;6(4):447-54.

9. Szymanska E. Construction of the model of health tourism innovativeness. Procedia Soc Behav Sci. 2015;213:1008-14.

10. Smith M, Puczko L. Health and wellness tourism. Oxford: Elsevier; 2009.

11. Semotlova M. Medical tourism [dissertation]. Prague: University of Economics; 2012. (In Czech.)

12. Benowitz I, Gaines J. Medical tourism. In: Brunette GW, Nemhauser JB, editors. CDC yellow book 2020: health information for international travel. Oxford University Press; 2019.

13. Health-tourism. Medical tourism statistics and facts [Internet]. [cited $2018 \mathrm{Aug} 10]$. Available from: https://www.health-tourism.com/medicaltourism/statistics/.

14. Han H, Hyun SS. Customer retention in the medical tourism industry: impact of quality, satisfaction, trust, and price reasonableness. Tour Manag. 2015;46:20-9.

15. Lunt N, Horsfall D. Medical tourism. In: Culyer AJ, editor. Encyclopedia of health economics. Elsevier; 2014. p. 263-70.

16. Pocock NS, Phua KH. Medical tourism and policy implications for health systems: a conceptual framework from a comparative study of
Thailand, Singapore and Malaysia. Global Health. 2011 May 4;7:12. doi: 10.1186/1744-8603-7-12.

17. Moher D, Liberati A, Tetzlaff J, Altman D; The PRISMA Group. Preferred reporting items for systematic reviews and meta-analysis: the PRISMA statement. PLoS Med. 2009;6(7):e1000097. doi: 10.1371/journal. pmed.1000097.

18. Lunt N, Horsfall D, Hanefeld J. Medical tourism: a snapshot of evidence on treatment abroad. Maturitas. 2016;88:37-44.

19. Herrick DM. Medical tourism: global competition in health care. Dallas: National Center for Policy Analysis; 2007.

20. ScienceDirect. Medical tourism [Internet]. [cited 2018 Aug 10]. Available from: https://www.sciencedirect.com/search?qs=medical\%20tourism.

21. Chuang TC, Liu JS, Lu YY, Lee Y. The main paths of medical tourism: from transplantation to beautification. Tour Manag. 2014;45:49-58.

22. Smith PC, Forgione D. Global outsourcing of healthcare: a medical tourism model. J Inform Technol Case Appl Res. 2007;9(3):19-30.

23. Caballero-Danell S, Mugomba C. Medical tourism and its entrepreneurial opportunities: a conceptual framework for entry into the industry [Internet]. Gothenburg: University of Gothenburg; 2007 [cited 2018 Aug 10]. Available from: http://gupea.ub.gu.se/dspace/handle/2077/4671.

24. Ye BH, Yuen PP, Qiu HZ, Zhang VH. Motivation of medical tourists: an exploratory case study of Hong Kong medical tourists. In: 14th Asia Pacific Tourism Association Annual Conference; 2008 July 9-12; Bankok, Thailand.

25. Ganguli S, Ebrahim AH. A qualitative analysis of Singapore's medical tourism competitiveness. Tour Manag Perspect. 2017;21:74-84.

26. Khan S, Alam SA. Kingdom of Saudi Arabia: a potential destination for medical tourism. J Taibah University Med Sci. 2014;9(4):257-62.

27. Perkins E. Seniors on the go: medical tourism: is it for you. Chicago Tribune [Internet]. 2015 Jul 21 [cited 2018 Aug 10]. Available from: http://www.chicagotribune.com/lifestyles/travel/sns-201507210000-tms--travelpkctnxf-b20150721-20150721-column.html.

28. Moghavvemi S, Ormond M, Musa G, Isa CRM, Thirumoorthi T, Mustapha MZB, et al. Connecting with prospective medical tourists online: a cross-sectional analysis of private hospital websites promoting medical tourism in India, Malaysia and Thailand. Tour Manag. 2017;58:154-63.

29. Abubakar AM, Ilkan M. Impact of online WOM on destination trust and intention to travel: a medical tourism perspective. J Destin Mark Manag. 2016;5(3):192-201.

30. European Commission. Preferences of Europeans towards tourism [Internet]. [cited 2018 Aug 10]. Available from: http://ec.europa.eu/geninfo/ query/resultaction.jsp?swlang=en\&QueryText=senior+travellers\&sbtSe $\operatorname{arch}=$ Search.

31. Alsharif M, Labonte R, Zuxun L. Patients beyond borders: a study of medical tourists in four countries. Glob Soc Policy. 2010;10(3):315-35.

32. Yu JY, Ko TG. A cross-cultural study of the perceptions of medical tourism among Chinese, Japanese and Korean tourists in Korea. Tour Manag. 2012;33(1):80-8.

33. Heung VCS, Kucukusta D, Song H. Medical tourism development in Hong Kong: an assessment of the barriers. Tour Manag. 2011;32(5):995-1005.

34. Rokni L, Park SH, Avci T. Improving medical tourism services through human behaviour and cultural competence. Iran J Public Health. 2019;48(11):1988-96.

35. Johnston R, Crooks VA, Snyder J, Kingsbury P. What is known about the effects of medical tourism in destination and departure countries? A scoping review. Int J Equity Health. 2010 Nov 3;9:24. doi: 10.1186/14759276-9-24.

36. Crooks VA, Turner L, Cohen IG, Bristeir J, Snyder J, Casey V, et al. Ethical and legal implications of the risks of medical tourism for patients: a qualitative study of Canadian health and safety representatives' perspectives. BMJ Open. 2013;3(2):e002302. doi: 10.1136/bmjopen-2012-002302.

37. Snyder J, Crooks VA, Wright A, Johnston R. Medical tourism facilitators: ethical concerns about roles and responsibilities. In: Hodges JR, Turner L, Kimball AM, editors. Risks and challenges in medical tourism: understanding the global market for health services. Santa Barbara: Praeger; 2012.

38. Mohamad WN, Omar A, Haron MS. The moderating effect of medical travel facilitators in medical tourism. Procedia Soc Behavior Sci. 2012;65:358-63.

39. Skountridaki L. Barriers to business relations between medical tourism facilitators and medical professionals. Tour Manag. 2017;59:254-66.

Received March 5, 2019

Accepted in revised form July 4, 2020 